University of Nebraska - Lincoln

DigitalCommons@University of Nebraska - Lincoln

Faculty Publications, Department of

Mathematics

Mathematics, Department of

8-28-2018

Predicting impacts of chemicals from organisms to ecosystem service delivery: A case study of endocrine disruptor effects on trout

\author{
Valery E. Forbes \\ University of Minnesota-St.Paul, veforbes@umn.edu \\ Steve Railsback \\ Lang Railsback \& Associates \\ Chiara Accolla \\ University of Minnesota- St. Paul, caccolla@umn.edu \\ Bjorn Birnir \\ University of California Santa Barbara, birnir@math.ucsb.edu \\ Randall J.F. Bruins \\ US Environmental Protection Agency, bruins.randy@epa.gov
}

See next page for additional authors

Part of the Applied Mathematics Commons, and the Mathematics Commons

Forbes, Valery E.; Railsback, Steve; Accolla, Chiara; Birnir, Bjorn; Bruins, Randall J.F.; Ducrot, Virginie; Galic, Nika; Garber, Kristina; Harvey, Bret C.; Jager, Henriette I.; Kanarek, Andrew; Pastorok, Robert; Rebarber, Richard; Thorbek, Pernille; and Salice, Chris J., "Predicting impacts of chemicals from organisms to ecosystem service delivery: A case study of endocrine disruptor effects on trout" (2018). Faculty Publications, Department of Mathematics. 229.

https://digitalcommons.unl.edu/mathfacpub/229

This Article is brought to you for free and open access by the Mathematics, Department of at DigitalCommons@University of Nebraska - Lincoln. It has been accepted for inclusion in Faculty Publications, Department of Mathematics by an authorized administrator of DigitalCommons@University of Nebraska - Lincoln. 


\section{Authors}

Valery E. Forbes, Steve Railsback, Chiara Accolla, Bjorn Birnir, Randall J.F. Bruins, Virginie Ducrot, Nika Galic, Kristina Garber, Bret C. Harvey, Henriette I. Jager, Andrew Kanarek, Robert Pastorok, Richard Rebarber, Pernille Thorbek, and Chris J. Salice 


\title{
Predicting impacts of chemicals from organisms to ecosystem service delivery: A case study of endocrine disruptor effects on trout
}

\author{
Richard Rebarber ${ }^{\mathrm{k}}$, Pernille Thorbek ${ }^{1}$, Chris J. Salice ${ }^{\mathrm{m}}$ \\ a Department of Ecology, Evolution and Behavior, University of Minnesota, St. Paul, MN, USA \\ b Lang Railsback \& Associates, Arcata, CA, USA \\ c Center for Complex and Nonlinear Science and Department of Mathematics, University of California Santa Barbara, Santa Barbara, CA, USA \\ d Systems Exposure Division, National Exposure Research Laboratory, US Environmental Protection Agency, Cincinnati, OH, USA \\ e Bayer AG, Crop Science Division, Monheim am Rhein, Germany \\ f Syngenta Crop Protection, LLC, Greensboro, NC, USA \\ ${ }^{g}$ Environmental Fate and Effects Division, Office of Pesticide Programs, United States Environmental Protection Agency, Washington, DC, USA \\ ${ }^{\text {h }}$ Pacific Southwest Research Station, USDA Forest Service, Arcata, CA, USA \\ i Environmental Sciences Division, Oak Ridge National Laboratory, Oak Ridge, TN, USA \\ ${ }^{\mathrm{j}}$ Ecology Group, Integral Consulting, Woodinville, WA, USA \\ ${ }^{\mathrm{k}}$ Department of Mathematics, University of Nebraska, Lincoln, NE, USA \\ ${ }^{1}$ Environmental Safety, Syngenta, Jealott's Hill International Research Centre, Bracknell, United Kingdom \\ ${ }^{\mathrm{m}}$ Environmental Science and Studies Program, and the Department of Biological Sciences, Towson University, Towson, MD, USA
}

Valery E. Forbes ${ }^{\mathrm{a}, *}$, Steve Railsback ${ }^{\mathrm{b}}$, Chiara Accolla ${ }^{\mathrm{a}}$, Bjorn Birnir ${ }^{\mathrm{c}}$, Randall J.F. Bruins ${ }^{\mathrm{d}, 1}$, Virginie Ducrot ${ }^{\mathrm{e}}$, Nika Galic ${ }^{\mathrm{f}}$, Kristina Garber ${ }^{\mathrm{g}}$, Bret C. Harvey ${ }^{\mathrm{h}}$, Henriette I. Jager ${ }^{\mathrm{i}}$, Andrew Kanarek ${ }^{\mathrm{g}}$, Robert Pastorok ${ }^{\mathrm{j}}$,

\section{H I G H L I G H T S}

- Effects of an endocrine disruptor on individuals and populations of trout are modeled.

- Impacts on populations are not directly proportional to impacts in individuals.

- Importance of endocrine disruption and inter-species competition is compared.

- Translating model outputs to ecosystem services facilitates decision making.

\section{A R T I C L E I N F O}

\section{Article history:}

Received 9 July 2018

Received in revised form 24 August 2018

Accepted 25 August 2018

Available online 28 August 2018

Editor: D. Barcelo

\section{G R A P H I C A L A B S T R A C T}

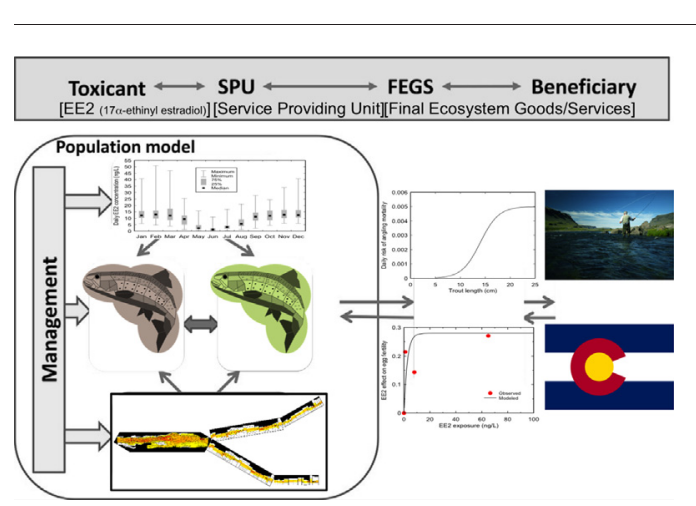

\section{A B S T R A C T}

We demonstrate how mechanistic modeling can be used to predict whether and how biological responses to chemicals at (sub)organismal levels in model species (i.e., what we typically measure) translate into impacts on ecosystem service delivery (i.e., what we care about). We consider a hypothetical case study of two species of trout, brown trout (Salmo trutta; BT) and greenback cutthroat trout (Oncorhynchus clarkii stomias; GCT). These hypothetical populations live in a high-altitude river system and are exposed to human-derived estrogen ( $17 \alpha$-ethinyl estradiol, EE2), which is the bioactive estrogen in many contraceptives. We use the individualbased model inSTREAM to explore how seasonally varying concentrations of EE2 could influence male spawning

\footnotetext{
* Corresponding author at: Department of Ecology, Evolution and Behavior, 123 Snyder Hall, 1475 Gortner Ave, St. Paul, MN 55108, USA.

E-mail address: veforbes@umn.edu (V.E. Forbes).

1 (Retired)
} 
Keywords:

Ecological modeling

Ecological risk assessment

Ecosystem services

FEGS

Individual-based model

Trout and sperm quality. Resulting impacts on trout recruitment and the consequences of such for anglers and for the continued viability of populations of GCT (the state fish of Colorado) are explored. inSTREAM incorporates seasonally varying river flow and temperature, fishing pressure, the influence of EE2 on species-specific demography, and inter-specific competition. The model facilitates quantitative exploration of the relative importance of endocrine disruption and inter-species competition on trout population dynamics. Simulations predicted constant EE2 loading to have more impacts on GCT than BT. However, increasing removal of BT by anglers can enhance the persistence of GCT and offset some of the negative effects of EE2. We demonstrate how models that quantitatively link impacts of chemicals and other stressors on individual survival, growth, and reproduction to consequences for populations and ecosystem service delivery, can be coupled with ecosystem service valuation. The approach facilitates interpretation of toxicity data in an ecological context and gives beneficiaries of ecosystem services a more explicit role in management decisions. Although challenges remain, this type of approach may be particularly helpful for site-specific risk assessments and those in which tradeoffs and synergies among ecosystem services need to be considered.

(C) 2018 Elsevier B.V. All rights reserved.

\section{Introduction}

This study provides a proof of concept to demonstrate how the kinds of effects typically measured in ecological risk assessments (i.e., lethal or sublethal effects on individual organisms) can be mechanistically and quantitatively linked to impacts of concern to society. Doing so can strengthen the scientific basis of risk assessments and thereby better inform management and policy decisions.

Assessing and managing the risks of chemicals and other human influences on ecological systems often involves extrapolating information collected at lower levels of biological organization to likely impacts at higher levels of organization. One reason for this is that effects at lower levels (i.e., on individual organisms or suborganismal processes) may be more amenable to measurement at reasonable spatial and temporal scales and under controlled laboratory conditions. In contrast, particularly for larger, longer-lived species, effects at higher levels (i.e., populations, communities, ecosystems) often involve measurement over spatiotemporal scales that are impractical and confounded by environmental variability that is difficult to account for. Mechanistic effect models, defined as abstractions of real systems that represent biological, physical, and chemical processes and their consequences within and across levels of biological organization in a mechanistic way (Grimm and Martin, 2013), provide powerful tools for linking effects of stressors across levels of organization (Forbes and Calow, 2013; Hommen et al., 2015). Because they incorporate mechanistic relationships and express the linkages in quantitative terms, they facilitate an increased understanding of key phenomena and provide a more robust basis for management decisions.

For example, under current chemical legislation in many jurisdictions, assessment of chemical risks to the environment requires testing a handful of species, most frequently for effects on individual survival, growth and reproduction (EC, 2006; US EPA, 2017). This approach relies on the assumption that individual responses directly link with population dynamics, and hence persistence, of species in nature. However, relationships between the survival, growth, and reproduction of individuals and the dynamics of populations can be highly nonlinear (Forbes et al., 2008). Furthermore, such relationships are not the same across species due to differences in life history (Stark and Banks, 2003), and they may be further confounded by such factors as density dependence and environmental variability.

With increased efforts to articulate environmental protection goals in terms of ecosystem service delivery (i.e., benefits of the environment to people; MEA, 2005, Nienstedt et al., 2012), it becomes necessary to link risk assessment endpoints to relevant properties of ecosystem services and quantify the relationships between the ecosystem services and the resulting benefits to human well-being. Ideally, expressing protection goals in terms of ecosystem services should facilitate protection goal valuation and may be particularly helpful for informing management decisions when tradeoffs or synergies among multiple services need to be considered (Power, 2010; McKane et al., 2014). To avoid problems of double-counting that arise when both intermediate and final services are valued (e.g., water pollutant removal by wetlands, and the subsequent provision of that same water by streams), it is useful to focus specifically on final ecosystem goods and services (FEGS), which are those goods or services that are directly consumed or enjoyed by a human beneficiary (Boyd and Banzhaf, 2007; Nahlik et al., 2012).

In this study we demonstrate a recently developed framework (Forbes et al., 2017) that mechanistically and quantitatively links effects of toxic chemicals and other stressors from impacts on individuals to the delivery of FEGS. This case study developed as one of the outputs of a National Institute of Mathematical and Biological Synthesis (NIMBioS) working group (http://www.nimbios.org/workinggroups/WG_o2e). It employs a well-tested and publicly available individual-based model and is based on realistic though purely hypothetical scenarios. We seek to demonstrate how a quantitative, mechanistic approach can provide important insights into human impacts on complex ecological systems and a solid foundation for informing environmental management.

\section{Materials and methods}

We simulated effects of the synthetic estrogen compound, 17a-ethinyl estradiol (EE2), on trout populations and the FEGS they provide. We chose EE2 as a model substance because it is a reference chemical for investigating the mechanisms of action of endocrine-disrupting chemicals on individual fish, and there are widespread concerns regarding the occurrence and population-level effects of chemicals such as EE2, particularly in fish (Marty et al., 2017). The high estrogenic potency of EE2 has been demonstrated in laboratory and field studies of a number of fish species exposed over shorter periods (i.e., 21 days) or multiple generations (Caldwell et al., 2012). Observed effects include deformities, ovary degeneration, appearance of testis-ova, alteration of sex-ratio and higher mortality at early life stages, among others. In rainbow trout ( 0 . mykiss), EE2 has been shown to cause changes in sperm densities, reduction in testis mass, effects on embryonic development, and at higher exposures, complete mortality (Schultz et al., 2003). Therefore, data are available that can inform models linking effects observed in laboratory tests to the dynamics of wild populations (Marty et al., 2017). The case study simulates but does not attempt to represent actual populations of two coexisting trout species: greenback cutthroat trout (GCT), Oncorhynchus clarkii stomias and brown trout (BT), Salmo trutta. The GCT subspecies is classified as threatened under the U.S. Endangered Species Act and is currently believed to persist in a very few small tributaries of the Arkansas River in the Rocky Mountains of Colorado. Historic threats to the GCT included mining pollution and water diversions, but competition and hybridization with introduced trout is likely the primary threat now (US FWS, 1998). The GCT is also the state fish of Colorado. The case study addresses a hypothetical population of GCT in a network of stream reaches with hydrology and 
temperature representing streams in the upper Arkansas River (details presented below). The population is assumed to coexist with a population of introduced brown trout (BT), Salmo trutta. BT is a favorite species for angling and has been introduced throughout the US in the late 1800s. Its native range includes Europe, North Africa and Western Asia. It is a known competitor of native fish species, specifically cutthroat trout (McHugh and Budy, 2006), and has been shown to substantially change and disrupt freshwater communities to which it has been introduced (Milardi et al., 2016).

\subsection{Population model}

In this study, we use version 5.0 of inSTREAM, an individual-based model (IBM) of trout (Railsback et al., 2009). We chose this model because it can represent key mechanisms through which EE2 and other stressors affect individual trout and how these individual-level effects impact population-level phenomena of interest. The model is wellestablished: the inSTREAM family of salmonid IBMs has been used in approximately 15 published studies since 1999, including a recent evaluation of its usefulness for complex management decision support (Dudley, 2018). We briefly describe the model here, focusing on parts especially relevant to this case study. Full documentation of the model and the input used here is provided by Railsback et al. (2009) and Harvey and Railsback (2012). A schematic of the model is provided in Appendix 1.

InSTREAM explicitly incorporates spatio-temporal variation in habitat. For this study, we represented a network of five stream reaches, each made up of multiple cells with varied characteristics. Habitat variables updated at the model's one-day time step include reach flow, temperature, turbidity, and the depth and velocity in each cell. Production of trout food is a function of each cell's depth and velocity. Predation risk varies among cells, depending on depth and availability of hiding cover.

The trout assemblage is represented by simulating individual fish and how their behavior and state change daily. Individuals are assumed to interact and compete with each other regardless of species, except for parameter differences discussed below, so differences among species emerge from how individual fish are affected by stressors and the environment. Model fish execute four actions daily. First is habitat selection, the primary adaptive behavior. In a size-based hierarchy (largest to smallest individual), fish select the nearby cell that provides the best tradeoff between growth and predation risk. The radius over which individuals select cells increases with fish size, and competition is represented via food depletion: large fish outcompete small fish for access to food.

Second, fish size is updated with daily growth. Growth depends on food intake, temperature, and the cost of swimming; growth rate varies therefore with water velocity, the optimal velocity increasing with fish size. The third action is survival: whether each fish lives or dies is a stochastic event but the probabilities of surviving several causes of mortality (e.g., predation by terrestrial animals, predation by other fish, starvation and disease) are deterministic functions of fish and habitat variables. Survival is the main source of stochasticity in the model. The last fish action is spawning: both male and female trout spawn at most once per year, on days when a number of criteria (e.g., for date, flow stability, and spawner age, size, and condition) are met.

Spawning by a female trout produces a redd, a nest containing eggs that then incubate until the eggs turn into new juvenile trout. Fecundity (number of eggs in a redd) increases as a power function of spawner length. InSTREAM treats each redd as an object with variables for the number of viable eggs and their development status. Development of eggs proceeds daily as a function of temperature until eggs reach a threshold for "emergence": conversion of each viable egg to a new trout. Some or all of the eggs in a redd can be killed by events including scouring by floods and extended low flows that dewater redds and expose eggs to more-extreme air temperatures. Therefore, in addition to the effects of EE2 described below, the number of juvenile trout produced each year is a function of the number and size of adult spawners and hydrologic conditions during incubation, especially the frequency of floods.

\subsubsection{Modifications to original model}

For this case study, we modified Version 5.0 of inSTREAM. The model was parameterized for GCT and BT, using respectively the same parameter values for rainbow and brown trout from Railsback et al. (2009). The only important difference assumed between species is spawning period: GCT spawn in early spring (April-May), and BT spawn in the fall (October-December). The minimum temperature for spawning was reduced from a standard value of $7{ }^{\circ} \mathrm{C}$ to $5{ }^{\circ} \mathrm{C}$ for GCT and $3{ }^{\circ} \mathrm{C}$ for BT to reflect the colder climate of the simulated study site.

Standard versions of inSTREAM do not explicitly represent mating as part of spawning, instead simply assuming that one male spawns whenever one female does. Because our simulated effects of EE2 (below) are on male trout, it was necessary to add mating to translate those effects into reproductive success. We therefore added the assumption that a female cannot spawn (produce a redd, lay eggs, and suffer the resulting weight loss) unless there is a male ready for spawning in the same stream reach. Both males and females spawn at most once per year.

We added a simple representation of angling impacts to the model because production of fish desired by anglers is one of the FEGS we quantify, and because we consider angling regulations (i.e., encouraging the removal of BT) as a management alternative for mitigating effects of EE2 on GCT. Catch-and-release angling is the norm in Rocky Mountain streams bearing wild trout populations, but angling can cause mortality due to the stress of being hooked (Bartholomew and Bohnsack, 2005) and the occasional intentional harvest. To represent how angling techniques and gear target larger fish, we assumed that the risk of angling mortality increases with trout length following a logistic curve, with a maximum daily risk of $0.5 \%$ (Fig. 1 ). Data to calibrate this function were not available, so angling mortality results of the model are treated as indicators for comparison of scenarios and not quantitative predictions. This mortality function determines which and how many fish die because of angling.

To evaluate the angling experience itself, we estimated the number of fish that were caught, including those safely released, by dividing the number that died by a factor representing the percentage of caught fish that die due to hooking stress and intentional harvest. This factor was set to $10 \%$, suggested by Bartholomew and Bohnsack (2005) as reasonable for a catch-and-release stream trout fishery. Because of repeated release, the estimated number of fish caught exceeds the catchable population.

To represent the seasonality of angling, a trout's daily risk of angling mortality was assumed to increase logistically with water temperature,

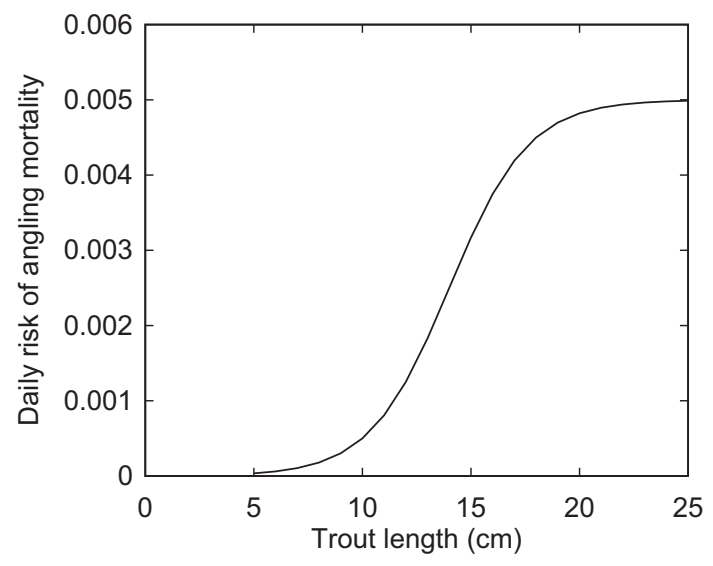

Fig. 1. Assumed relationship between trout length and a trout's daily risk of angling mortality. 
such that risk at $5{ }^{\circ} \mathrm{C}$ is $90 \%$ lower than at typical summer temperatures. This risk does not influence habitat selection.

\subsubsection{Model input}

We consider the simulated stream to consist of a network of five reaches, with no barriers to fish movement among them (Figs. 2 and $3 \mathrm{~A}$ ). We defined one mainstem reach, using the physical and hydraulic habitat representation of a site ("Dog Gulch", length $230 \mathrm{~m}$ ) on Clear Creek, CA, just downstream of Whiskeytown Reservoir (Railsback et al., 2015). In addition, we defined two 115-m fork reaches, which each drain into the mainstem reach, and two 75-m tributary reaches, which each drain into the upper end of a fork reach. The tributaries and forks use the habitat representation of Little Jones Creek CA tributaries and forks of Harvey and Railsback (2012). The combined extent of the simulated habitat is small compared to the upper Arkansas River watershed but sufficient, in our experience, to allow simulation of population-level results such as abundance and frequency of local extinction.

The simulated hydrologic and temperature regimes were designed to represent the native habitat of GCT. Daily flow and temperature data from the Arkansas River, CO (US Geological Survey gage 07086000, Arkansas River at Granite, CO) were obtained for the period of record, water years (October-September) 1993 to 2016. Mainstem flows (Fig. 3B) were adjusted by the ratio of mean flow at the site where habitat data were developed (Clear Creek and Little Jones Creek, CA) to mean flow at the Arkansas River gage. Small differences in flow between the two forks, and between the two tributaries, were induced by using slightly different slopes and intercepts in the relationships between Arkansas River and model reach flows. Temperature input was unmodified from data measured at gage 394220106431500, and the same values were used for all reaches (Fig. 3C). Turbidity was assumed to be negligible.

\subsubsection{Model calibration}

Male GCT have been reported to spawn for the first time in their second summer and females in their third or fourth (USFWS, 2017; Coleman, 2007). However, sexual maturity and fecundity are more closely related to size than age in salmonids, and female GCT have been reported to reach sexual maturity between 14.6 and $18 \mathrm{~cm}$ depending on location (Coleman, 2007). Elsewhere, adult GCT have been defined as fish $>12 \mathrm{~cm}$ in total length (USFWS, 1998). For our case study, we chose $15 \mathrm{~cm}$ as the minimum length at spawning. Generally, few fish reach sizes larger than $25 \mathrm{~cm}$ in the small, high elevation streams with short growing seasons where GCT populations are found today (Coleman, 2007). Because GCT are so rare, few field observations are available for model calibration. Instead, calibration targets were based on observed fall abundance and size of coastal cutthroat trout at Little Jones Creek, with the abundance adjusted for the larger size of the mainstem reach. The abundance target was thus a mean of 50 sexually mature trout for both species. Length targets were: mean lengths of $11 \mathrm{~cm}$ at age $1,15 \mathrm{~cm}$ at age 2 , and $20 \mathrm{~cm}$ for age 3 and older, averaged over both species. Calibration was conducted simply by adjusting food availability and the overall risk of predation by terrestrial animals to obtain long-term average results close to the calibration targets.

\subsubsection{Effects of EE2 on trout}

We modified inSTREAM to represent two ways that EE2 affects the reproductive biology of individual trout. Neither mechanism assumes acute toxicity of EE2. Both mechanisms depend on the exposure of male trout to EE2 as testes and sperm develop before spawning. Therefore, for both mechanisms the exposure variable was the mean EE2 concentration (ng/L) a male trout experienced over 90 -d prior to spawning. This window was based on EE2 effects observed on trout in laboratory studies in which sustained exposure during similar time frames was necessary for effects to occur (Schultz et al., 2012, 2013).

The first mechanism is a reduction in the success of egg fertilization. Brown et al. (2007) observed that males exposed to low ( $\leq 1 \mathrm{ng} / \mathrm{L}$ ) concentrations of EE2 produced sperm capable of fertilizing eggs, but there was about a $15 \%$ decline in egg survival compared to controls 19 days post fertilization. We modeled this effect using an inverse exponential function that caused the fraction of fertilized eggs that die to rise sharply and asymptotically from 0.0 to 0.28 as exposure to EE2 increases to reflect the data of Brown et al. (2007) and Schultz et al. (2012, 2013) (Fig. 4). This relationship can be modeled as: EE2EggEffect $=$ EE2MaxEggEffect $\times(1.0-\exp ($ EE2Param $\times$ EE2Exposure $))$ where EE2EggEffect is the fraction of fertilized eggs that die instead of develop; EE2MaxEffect is the asymptotic value of EE2EggEffect (estimated as $0.28)$; EE2Param is a scaling parameter estimated by calibration as -0.4 , and EE2Exposure is the average EE2 concentration the male experienced over the $90 \mathrm{~d}$ prior to spawning. Because EE2 concentration depends on river flow (Section 2.2, below), exposure varies among years and (to a lesser degree) among individual fish and is therefore an output of the model, not an input.

The number of viable eggs was therefore assumed equal to fecundity $x$ fishSpawnEggViability $\times(1-$ EE2EggEffect $)$, where fecundity is the number of eggs produced by a female upon spawning (a nonlinear function of female length) and fishSpawnEggViability is inSTREAM's parameter for the fraction of eggs successfully fertilized under normal conditions. Fertilization success in wild populations is difficult to estimate; the standard value in inSTREAM is 0.8 , but to correspond with the data of Brown et al. (2007), we used a value of 0.7. EE2 can also affect fish by preventing males from spawning by inhibiting the

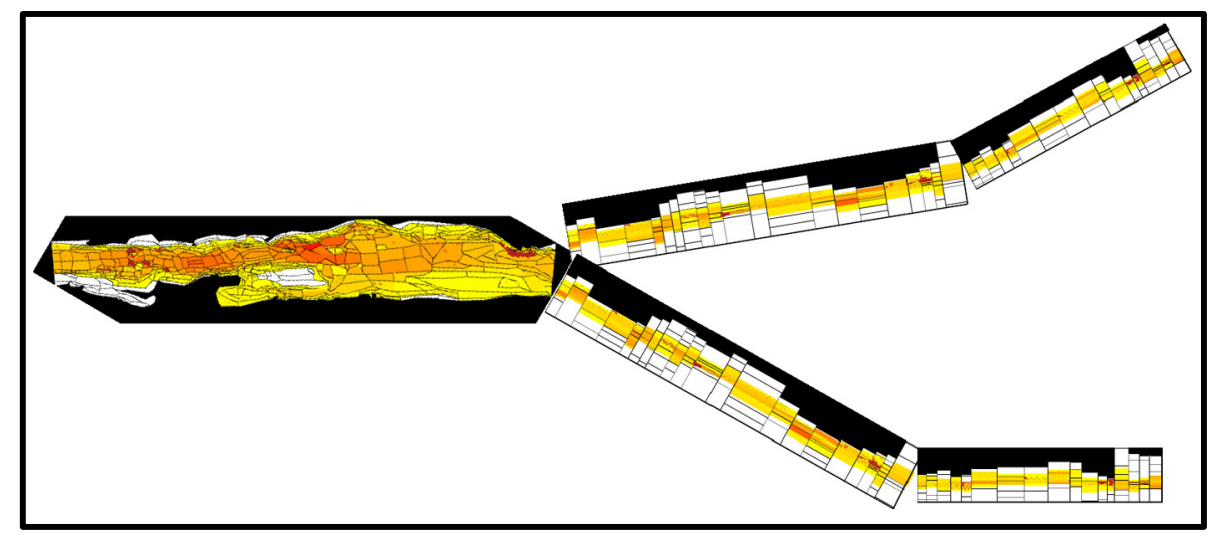

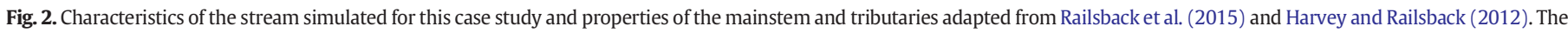
colors represent different velocities with darker (orange) shades representing higher velocities and lighter (yellow) shades representing lower velocities. 
A)

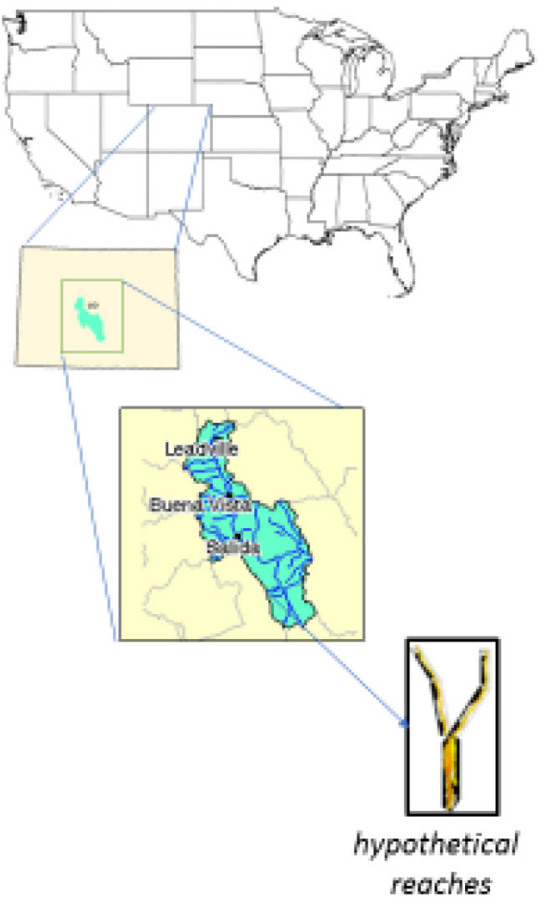

B) USGS 0708600

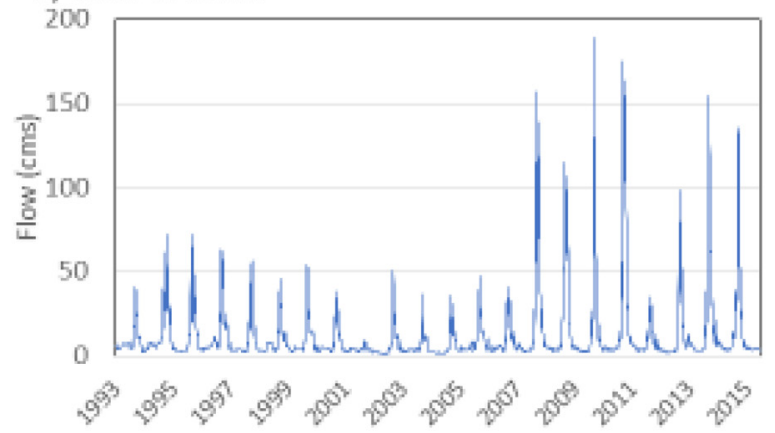

C) USGS 394220106431500

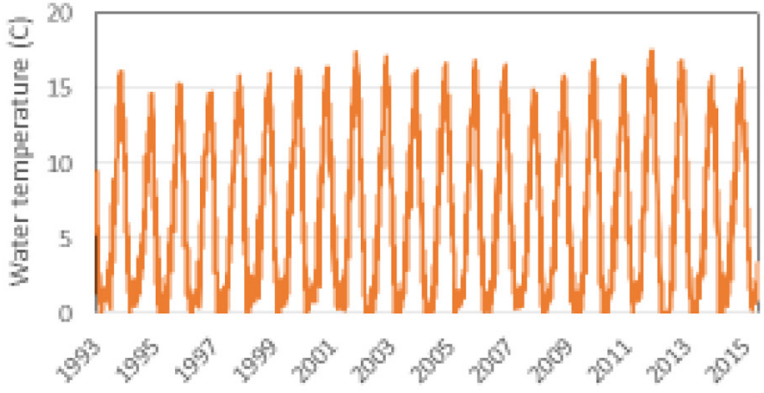

Fig. 3. A) Colorado, USA location of river subbasin used to characterize environmental drivers B) mean daily flow, $\mathrm{cms}$, and C) mean daily water temperature, ${ }^{\circ} \mathrm{C}$, in simulations.

development of gonads. This effect increases with pre-spawning exposure to EE2.

No literature data are currently available for EE2 (or other endocrine-active substances) that quantitatively describe how exposure concentration and duration affect gonad development in male trout. However, in laboratory studies with rainbow trout, no effects on male spawning were observed at constant EE2 exposure concentrations of $2 \mathrm{ng} / \mathrm{L}$ for a period of five months, whereas at $20 \mathrm{ng} / \mathrm{L}$ no fish spawned (Irv Schultz, personal communication). Schubert et al. (2008) exposed brown trout to a mixture of estrogen-active endocrine disruptors for 5 months. No effect on fertility occurred at low exposure concentrations (estrone $(\mathrm{E} 1)=14 \mathrm{ng} / \mathrm{L}$, estradiol $(\mathrm{E} 2)=2 \mathrm{ng} / \mathrm{L}$, and nonylphenol $(\mathrm{NP})=111 \mathrm{ng} / \mathrm{L})$, whereas higher concentrations

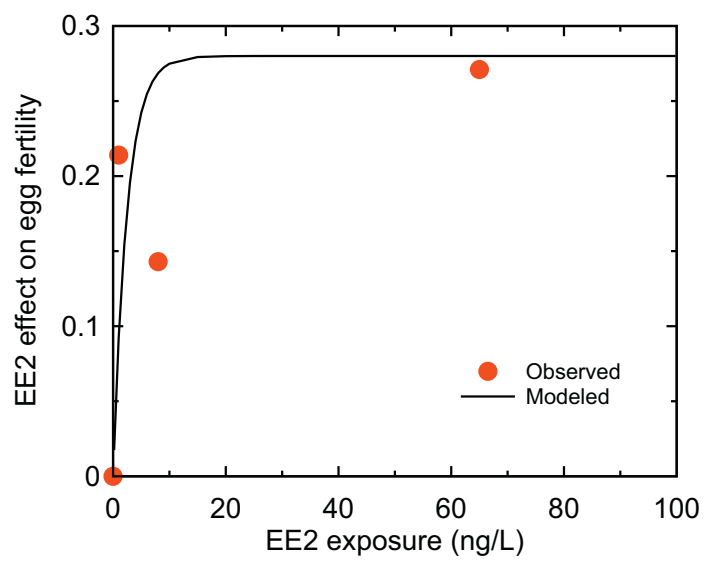

Fig. 4. Exposure-response relationship for the effect of EE2 on egg viability. The observed data are from Brown et al. (2007); the modeled values were produced by the inSTREAM relation described in the text. The $\mathrm{X}$ axis is the mean EE2 concentration (ng/L) a male trout experienced over a $90-\mathrm{d}$ period prior to when the effect was simulated. The $Y$ axis is the \% mortality of fertilized eggs caused by EE2 exposure of males.
$(\mathrm{E} 1=56.6 \mathrm{ng} / \mathrm{L}, \mathrm{E} 2=7 \mathrm{ng} / \mathrm{L}, \mathrm{NP}=1006 \mathrm{ng} / \mathrm{L})$ caused a 9\% decrease in fertilization success. Werner et al. (2006) showed that lake trout were insensitive to a 3-year exposure to 5-6 ng/L of EE2.

We assumed that each adult male trout is in a particular gonadal development status at the start of its spawning season, i.e., ready for spawning or not (Railsback et al., 2009). This status is assumed to depend on previous exposure to EE2. It is modeled as a stochastic event with the probability of becoming ready to spawn as a declining logistic function of EE2Exposure evaluated at the start of the spawning season (April 1 for GCT, October 1 for BT). The logistic function was parameterized so that the probability of a male becoming ready to spawn is $90 \%$ at EE2Exposure $=2 \mathrm{ng} / \mathrm{L}$ and $10 \%$ at $20 \mathrm{ng} / \mathrm{L}$. We assume that this status is not reversible within a spawning season, but that effects are reversible between spawning seasons, i.e., a male can spawn in subsequent years even if it did not spawn in one year, and males ready one year may not spawn in subsequent years. Because we assume males spawn at most once per year, reductions in the number of ready males cannot be compensated for by multiple spawning of the males that do mature. We assume that GCT and BT have identical exposure-response relationships for EE2.

\subsection{Exposure of trout to EE2}

Reported values for EE2 concentrations in effluents and surface waters typically range from $<0.05 \mathrm{ng} / \mathrm{L}$ up to $9 \mathrm{ng} / \mathrm{L}$ (Schultz et al., 2003), but values for U.S. waters have been reported to be as high as 73 to $831 \mathrm{ng} / \mathrm{L}$ (Kolpin et al., 2002). For our case study, EE2 exposure was modeled as a function of a daily contaminant loading (rate of EE2 mass discharged to streams, habEE2Loading, in units of $\mathrm{ng} / \mathrm{s}$ ). Each of the five simulated reaches had its own EE2 loading (i.e., due to a point source discharge at its upper end), in addition to what it received from upstream reaches, if any. We assumed no loss or transformation of EE2 over the simulated reaches. For the simulations reported here, we assumed constant loading over time, so the EE2 concentration in each reach was inversely related to daily flow, due to dilution. Therefore, the simulated concentration varied on a daily basis. Although constant loading from a point source (e.g., a waste water treatment plant 
(WWTP)) may not occur in reality (e.g., due to differences in EE2 input from the population served by that WWTP), it is expected that daily concentrations in natural waters will vary. Therefore, this approach allows us to simulate effects of varying concentrations over time by accounting for different volumes of water. The daily concentration of EE2 $(\mathrm{ng} / \mathrm{L})$ in each reach was therefore calculated as habEE2Loading $(\mathrm{ng} / \mathrm{s}) /\left[\right.$ flow $\left.\left(\mathrm{m}^{3} / \mathrm{s}\right) \times 1000 \mathrm{~L} / \mathrm{m}^{3}\right]$, where habEE2Loading is the sum of loading to the reach and any upstream reaches, and where flow is the reach's daily stream flow. The relationship among loading, concentration, and flow is nonlinear, so calculating the loading that produces a desired mean stream concentration (i.e. sufficiently high to elicit adverse effects in exposed male fish) was not straightforward. By dividing loading by daily flow and averaging over all simulated days, we determined that the following constant loadings (ng/s) produce a long-term mean concentration of $10 \mathrm{ng} / \mathrm{L}$ in our case study: Mainstem: 35,000; Left Fork: 2600; Right Fork: 2660; Left Tributary: 3500; Right Tributary: 3340 . These loadings sum to $47,100 \mathrm{ng} / \mathrm{s}$ or $4.07 \mathrm{~g} / \mathrm{d}$, and were used as our baseline exposure scenario. The mean concentration of $10 \mathrm{ng} / \mathrm{L}$ in our baseline scenario is relatively high but not unreasonable compared to concentrations that may be reached in some natural flowing water bodies (Kolpin et al., 2002; Schultz et al., 2003); this scenario included substantial seasonal variation (Fig. 5).

\subsection{Simulation experiment design}

We simulated the effects of five discrete EE2 loading scenarios: 0, $0.5,1,2$, and 3 times the baseline loadings. These scenarios encompass a range of EE2 exposure concentrations that would be expected to result in no effects $(0 \mathrm{ng} / \mathrm{L})$ to severe effects $(\sim 25 \mathrm{ng} / \mathrm{L})$ on male trout (Schultz et al., 2003; Brown et al., 2007). For each of these scenarios we conducted 10 replicate simulations so that the magnitude of EE2 effects could be compared to the magnitude of natural variation in trout populations. Replicates were generated not by simply changing the sequence of pseudorandom numbers in the inSTREAM simulations (the model is not highly stochastic) but by randomly shuffling the sequence of input data years (daily flow and temperature input values, starting July 1 ). Hence, the replicates represent variation due to patterns of year-toyear variability in weather and hydrology.

We examined two population-level model results that represent the FEGS provided by GCT and BT, and several individual-level results necessary to understand the population-level outcomes. The primary FEGS that we consider are the abundance of catchable (i.e., adult-sized) trout and persistence of the simulated GCT population. Population

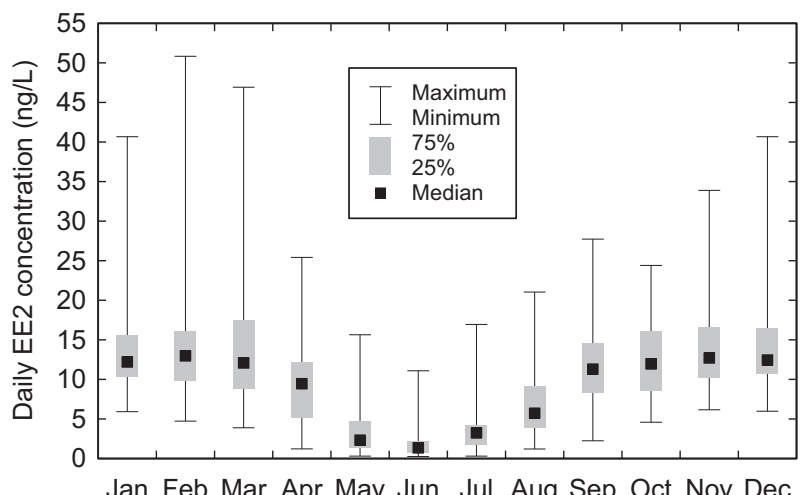

Fig. 5. The simulated distribution of daily concentrations of EE2 in the left tributary reach. Concentrations were calculated by dividing EE2 loading (assumed constant over time) by daily flows; therefore, high concentrations occur during low flows (most common in winter when precipitation is mainly snow) and low concentrations during high flows (which are most frequent during spring-summer snow melt). Flows were estimated by adjusting gage data from water years $1994-2015$ as described in Section 2.1.2. Other reaches exhibit similar patterns. persistence of GCT was evaluated as the mean number of years the simulated GCT population persisted over the 10 replicate simulations. This years-to-extirpation measure has a maximum value of 22 years, the length of the simulations. Abundance of catchable trout is evaluated simply as the abundance of age 1 and older trout in late September. The estimated number of trout caught is closely related to the catchable population, as explained earlier, albeit much larger due to individuals being caught repeatedly. We also examined several individual-level results that help explain the FEGS results. These results are the mean EE2 exposure of males that spawn (the value of EE2Exposure evaluated at the time of spawning), the fraction of potential male spawners (males with an age of 1 or higher at the start of the spawning season) that are ready for spawning, and the number of spawning events (indicating the effect of EE2 on male readiness and effects of EE2 on spawner abundance). To reduce the effects of initial conditions (all simulations started with the same initial trout populations), results for abundance did not include output from the first two of the 22 simulated years.

We then conducted several additional sets of simulation experiments to elucidate the importance of different processes affecting the GCT population. First, to evaluate the relative importance of the two simulated effects of EE2 on male reproductive biology, we conducted a second set of simulations in which the first mechanism-reduced egg viability-was turned off. Second, to illustrate the relative importance of the two stressors on GCT, EE2 and competition with BT, we repeated the EE2 exposure simulations in the absence of BT. Finally, to illustrate a realistic management measure to mitigate EE2 effects on GCT and enhance their populations, we simulated a simple change in fisheries management: encouraging angler removal of BT but not GCT. We simulated this management action by increasing the maximum daily risk of angling mortality from $0.5 \%$ to $1.5 \%$ for BT.

\subsection{Ecosystem services valuation}

Our goal in this case study is to highlight the potential for using mechanistic modeling to quantify sub-organismal effects of stressors on ecosystem services. In this case study, a meaningful effect on anecosystem service implies a change in economic value. Estimation of value depends on (a) identifying specific ecosystem services that are affected by case study scenarios, (b) determining the corresponding ecological qualities that provide those services, (c) quantifying the changes in those qualities and (d) estimating the value, for example through an economic evaluation such as beneficiary willingness-to-pay (WTP). For purposes of this proof-of-concept study, our goal is only to demonstrate the feasibility of determining economic values, not to estimate those values.

Using US EPA's FEGS Classification System (Landers and Nahlik, 2013), we identified two FEGS-beneficiary combinations that are applicable to our case and involve FEGS which can be approximated by our model: "fish - recreational anglers," and "presence of the environment - people who care" (Table 1). We interpret "fish" that benefit anglers as BT and GCT of catchable size, estimated in our model runs as fish of age $1+$, and recreational anglers to be those who fish in Colorado streams supporting BT and GCT. We interpret "presence of the environment" as the presence of streams, or stream reaches, supporting a population of GCT. InSTREAM results show the time to extirpation of GCT in the modeled stream reaches. We interpret "people who care" as households, particularly in Colorado, that would be willing to pay something to help ensure the continued survival of Colorado's State Fish, even if they never intend to fish for or observe them. We added a further FEGS-beneficiary combination, "fish - people who care," that is not currently listed in the FEGS-CS matrix but is warranted by observations of household willingness to pay for the existence, or increase, of threatened salmonid populations (Loomis and Richardson, 2008).

The value of a change in FEGS experienced by beneficiaries can often be revealed by the beneficiary's expenditures (e.g., the travel-cost 
Table 1

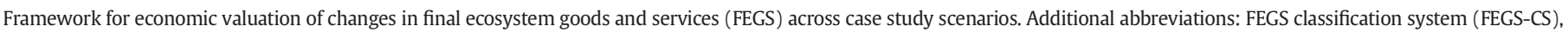
brown trout (BT), greenback cutthroat trout (GCT), and willingness-to-pay (WTP), standard error of the mean (SE).

\begin{tabular}{|c|c|c|c|c|c|}
\hline \multicolumn{2}{|l|}{ FEGS } & \multicolumn{2}{|l|}{ Beneficiary } & \multirow[t]{2}{*}{ Examples of benefit transfer data } & \multirow{2}{*}{$\begin{array}{l}\text { Corresponding model endpoint; and } \\
\text { valuation feasibility }\end{array}$} \\
\hline From FEGS-CS & In case study & From FEGS-CS & In case study & & \\
\hline Fish (in the water) & $\begin{array}{l}\text { Population of catchable } \\
\text { (i.e., adult) BT or GCT }\end{array}$ & $\begin{array}{l}\text { Recreational } \\
\text { anglers }\end{array}$ & $\begin{array}{l}\text { Recreational anglers } \\
\text { on Colorado streams } \\
\text { supporting BT or GCT }\end{array}$ & $\begin{array}{l}\text { WTP per angler-day (Snake River) }=\$ 85 \\
\text { WTP per additional wild trout caught }= \\
\$ 12-23 \text { (Loomis, 2005) }\end{array}$ & $\begin{array}{l}\text { Change in catch of BT }+ \text { GCT } \\
\text { (estimated as function of catchable } \\
\text { populations); valuation feasibile }\end{array}$ \\
\hline Fish (in the water) & $\begin{array}{l}\text { Population of countable } \\
\text { (i.e., adult) GCT }\end{array}$ & People who care & $\begin{array}{l}\text { Households in } \\
\text { Colorado }\end{array}$ & $\begin{array}{l}\text { Household WTP per } 1000 \text { wild salmon }= \\
\$ 63(\mathrm{SE}=\$ 32) \\
\text { WTP for } 1 \% \text { change in wild salmon } \\
\text { population }=\$ 0.84(\mathrm{SE}=\$ 0.11) \\
\text { (Loomis and Richardson, } 2008)\end{array}$ & $\begin{array}{l}\text { Change in census of age } 1+\text { GCT; } \\
\text { valuation feasibile }\end{array}$ \\
\hline $\begin{array}{r}\text { Presence of the } \\
\text { environment }\end{array}$ & $\begin{array}{l}\text { Presence of streams } \\
\text { supporting GCT }\end{array}$ & People who care & $\begin{array}{l}\text { Households in } \\
\text { Colorado }\end{array}$ & $\begin{array}{l}\text { Household WTP per mile for trout stream } \\
\text { restoration (Little Tennessee River in } \\
\text { western North Carolina, USA) }=\$ 4.54 \\
\text { (Holmes et al., 2004) }\end{array}$ & $\begin{array}{l}\text { Change in mean time to extirpation of } \\
\mathrm{GCT} \text {; valuation not feasibile }\end{array}$ \\
\hline
\end{tabular}

method; Wilson and Carpenter, 1999) or by surveying beneficiaries to ask how much they would be willing to pay (WTP) to use or enjoy a FEGS (e.g., contingent valuation; Wilson and Carpenter, 1999). Using a process termed benefits transfer, values determined for an ecosystem good in one setting can be transferred to another setting, although differences in the location, the policy setting, the beneficiaries or the nature of the good may introduce uncertainty (Newbold et al., 2018).

Economic studies are available to illustrate the feasibility and limitations of benefits transfer for catchable trout, the presence of GCT populations, and the presence of streams supporting GCT (Table 1). Loomis (2005) surveyed anglers on Snake River segments in Southeast Idaho and Southwest Wyoming in the US to determine both their WTP per day of angling and the change in WTP per additional trout caught. In our model, number caught is a function of the catchable population; therefore, modeled changes in trout populations could be valued, as long as the number of angler-days for streams affected by EE2 exposure could be estimated (Table 1). Loomis and Richardson (2008) reviewed literature on economic values of salmon in the US, where many salmon runs are threatened by dams and habitat degradation, and could be enhanced by restoration actions. Their meta-analysis estimated household WTP for changes in salmon populations (Table 1). Because GCT has been designated the state fish for Colorado, WTP for modeled changes in the countable (i.e., adult) GCT population are assumed to apply to households in the state.

Changes in the presence of streams supporting GCT populations are more difficult to value; we were unable to find data that could be used for benefits transfer for threatened salmonids expressed in terms of stream length. Holmes et al. (2004) found household WTP of \$4.54 per mile for trout stream restoration along the Little Tennessee River in western North Carolina, USA (Table 1), but this payment was for a bundle of ecosystem services associated with changes in stream habitat quality (abundance of game fish, water clarity, wildlife habitat, allowable water uses and ecosystem naturalness), rather than focusing just on game fish. Further, while the "Mean time to extirpation of GCT" metric is illustrative for scenario comparison, metapopulation modeling to account for local extirpations and reinvasions would be required for a realistic quantification of occupied reaches. Thus, this endpoint was not considered further in a valuation context.

\section{Results and discussion}

\subsection{Trout exposure and individual-level responses}

Across the five scenarios of increasing EE2 loading, exposure of pre-spawning trout to EE2 increased approximately linearly with loading, as expected (Fig. 6). Because of the difference in the timing of spawning between species, GCT exposure during a sensitive time window in the life cycle averaged almost 1.5 times that of BT. The 90-day period before BT spawning falls in mid- to late-summer months when EE2 concentrations are relatively low because dilution by river flow is high (Fig. 5), whereas for GCT this period falls in the winter months when river flow is lowest so EE2 concentrations are at their highest.

In our virtual experiment, EE2 exposure sharply decreased male spawning readiness (Fig. 7). For instance, the standard EE2 loading reduced the percentage of males prepared to spawn by $50 \%$ for GCT and by approximately $20 \%$ for BT in comparison to the zero-loading scenario. The percentage of GCT males prepared to spawn asymptotically approached zero as the loading increased from two to three times the standard loading. Because of their lower exposure, substantially higher percentages of BT males were prepared to spawn.

We found that the number of spawning events decreased as EE2 loading increased (Fig. 8). This was caused by decreases in simulated male spawning readiness, and the resulting population declines. Interestingly, however, the number of spawning events did not decrease as rapidly with EE2 loading as did male spawning readiness. This difference indicates the presence of a buffer mechanism that partially compensates for the declining percentage of ready males. The most likely mechanism is a surplus of male spawners: in inSTREAM simulations not all females spawn every year, so with an even sex ratio there are likely to be more males available than spawning females. Hence, the percentage of redds that can be fertilized does not decline as rapidly as the percentage of spawning males.

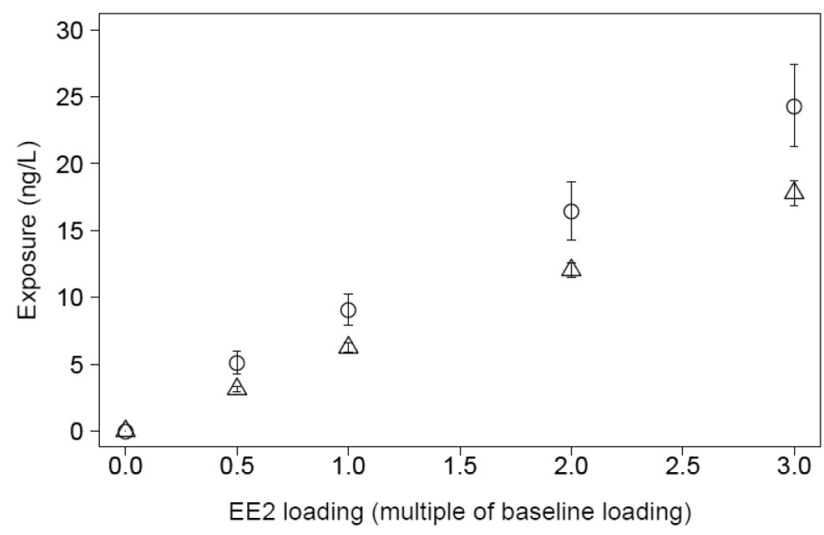

Fig. 6. Relationship between loading of EE2 and mean annual exposure of male trout during the 90 day period prior to spawning for BT (triangles) and GCT (circles). The baseline loading (factor $=1.0$ on the $\mathrm{X}$ axis) was calibrated to result in an annual average exposure concentration of EE2 of $10 \mathrm{ng} / \mathrm{L}$. Error bars indicate standard deviations around the mean of 10 replicate simulations. 


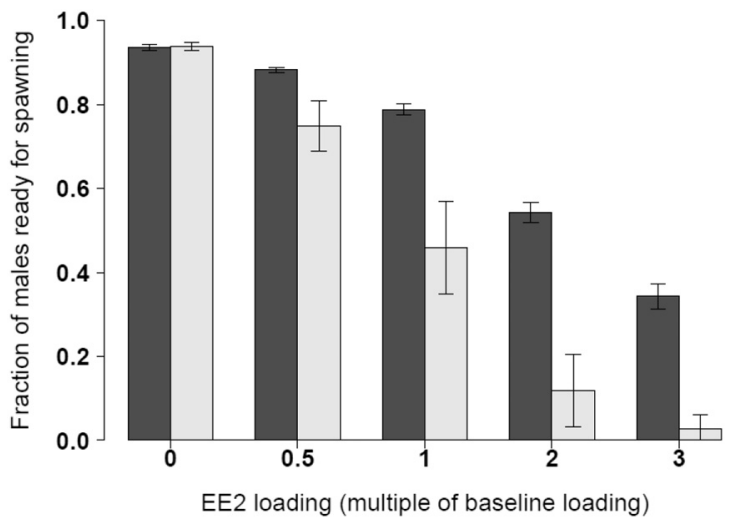

Fig. 7. Fraction of male trout ready for spawning. Black bars are BT and gray bars are GCT. The baseline loading (factor $=1.0$ on the $\mathrm{X}$ axis) was calibrated to result in an annual average exposure concentration of EE2 of $10 \mathrm{ng} / \mathrm{L}$. Error bars are standard deviations around the mean of 10 replicate simulations.

\subsection{Impacts of EE2 on trout populations}

In the absence of EE2, BT are more abundant than GCT, with an average of 22 GCT present in the whole stream system compared to $273 \mathrm{BT}$ (Fig. 9). Fall-spawning BT tend to dominate spring-spawning GCT because, as long as their redds are not washed out by winter storms, their juveniles hatch earlier in the spring and hence have a competitive (size) advantage from the beginning of life (e.g., Strange et al., 1992). In our simulations, winter conditions for BT redds were usually benign because winter storms produce snow instead of runoff. As EE2 loading increases, GCT abundance declines more steeply than BT abundance such that at the highest EE2 loading, the GCT population has declined by $73 \%$ and the BT population has declined by $32 \%$ compared to the zeroloading scenario. This difference in response between species is due to both the higher exposure of GCT during a sensitive time window discussed in Section 3.1 and the additional effect of competition by BT. The combined effects of EE2 and competition with BT caused the simulated GCT populations to be extirpated in all simulations, with the simulated time to extirpation decreasing as EE2 loading increased (Fig. 10). The extirpations further reduced the mean abundance reported in Fig. 9: calculation of mean abundance over a simulation included zeroes for years in which the population was extirpated.

\subsection{Relative impacts of the two EE2 effect mechanisms}

Section 3.2 illustrated that EE2 exposure to high concentrations ( $25 \mathrm{ng} / \mathrm{L}$ ) led to strong effects on simulated trout populations, especially

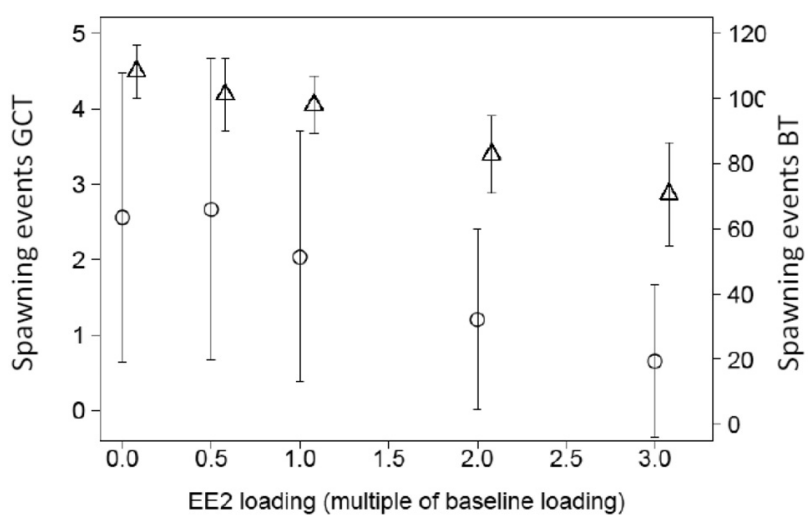

Fig. 8. Mean number of spawning events per year for BT (triangles) and GCT (circles). The baseline loading (factor $=1.0$ on the $\mathrm{X}$ axis) was calibrated to result in an annual average exposure concentration of EE2 of $10 \mathrm{ng} / \mathrm{L}$. Error bars are standard deviations around the mean of 10 replicate simulations.

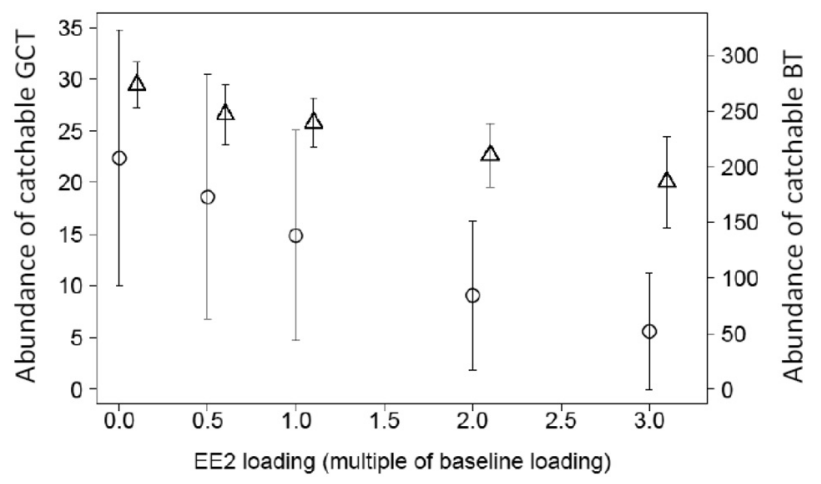

Fig. 9. Effect of EE2 loading on the mean fall abundance of catchable BT (triangles) and GCT (circles). The baseline loading (factor $=1.0$ on the $\mathrm{X}$ axis) was calibrated to result in an annual average exposure concentration of EE2 of $10 \mathrm{ng} / \mathrm{L}$. Error bars are standard deviations around the mean of 10 replicate simulations.

for GCT. Population-level effects are not linearly related to the reproductive effects. Understanding of population responses requires investigating how the various reproductive effects at play are inter-related. In particular, the question of which of the two mechanisms of EE2 is most responsible for the decrease in reproduction is important because neither mechanism is well understood. To address this question, we repeated the simulations with one mechanism-reduced egg fertilityturned off. These results therefore show the effect only of reduced readiness of males to spawn.

This virtual experiment produced a somewhat weaker effect of EE2 on trout abundance (Fig. 11, compared to Fig. 9). With the single EE2 mechanism, abundance of GCT decreased an average of $61 \%$ and BT $18 \%$ as EE2 loading was increased from zero to three times the baseline loading, compared to $73 \%$ and $32 \%$ declines with both EE2 mechanisms. The response of years to extirpation to EE2 loading in this experiment remained very similar to that with both EE2 mechanisms, indicating that the reduced male readiness represented here is the dominant effect mechanism over the full range of exposures. However, Fig. 11 indicates little effect of EE2 at loadings between zero and the baseline level (1.0). This suggests that a buffer mechanism is also at play that can partially make up for reduced male readiness to spawn (which in this experiment is the same as indicated in Fig. 7).

\subsection{Effects and management of competition with BT}

Our simulation results indicate that the GCT population is stressed even in the absence of EE2 since the population went extinct within

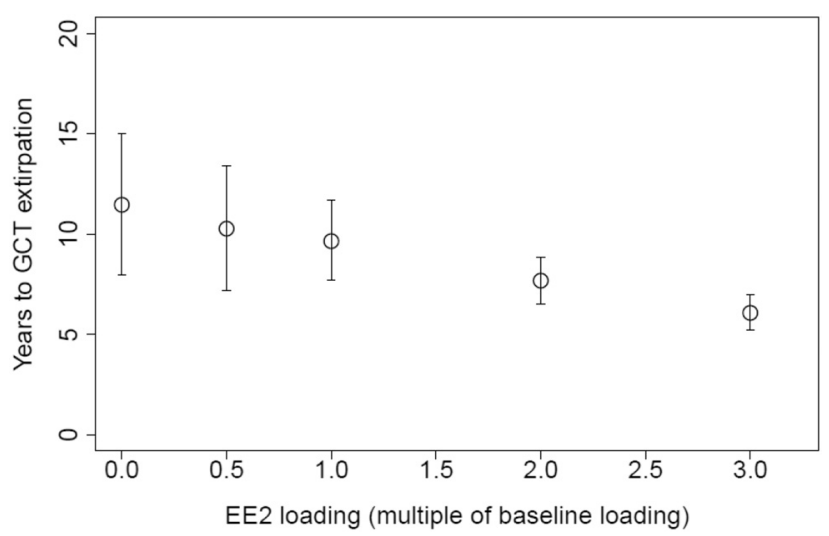

Fig. 10. Number of years until extirpation of the simulated GCT population, for the five EE2 loadings. The baseline loading (factor $=1.0$ on the $\mathrm{X}$ axis) was calibrated to result in an annual average exposure concentration of EE2 of $10 \mathrm{ng} / \mathrm{L}$. Error bars are standard deviations around the mean of 10 replicate simulations. 


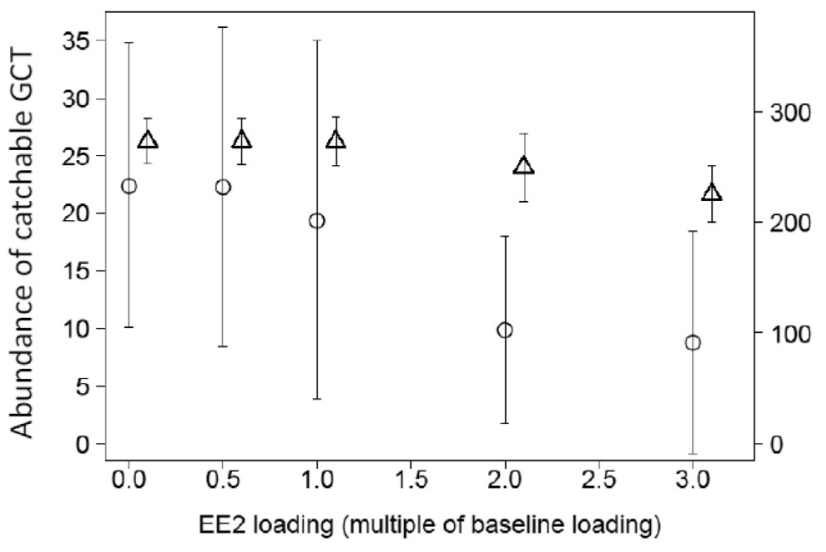

Fig. 11. Effect of EE2 loading on the mean fall abundance (number) of catchable BT (triangles) and GCT (circles) for simulations with EE2 effects on male spawning only (effects on egg fertility turned off). The baseline loading (factor $=1.0$ on the $\mathrm{X}$ axis) was calibrated to result in an annual average exposure concentration of EE2 of $10 \mathrm{ng} / \mathrm{L}$. Error bars are standard deviations around the mean of 10 replicate simulations.

the 22 year simulation period even with no EE2 present (Fig. 10). Because inSTREAM automatically represents the cumulative effects of both EE2 and BT on GCT populations, it is ideal for exploring the impacts of multiple stressors under ecologically realistic conditions. To understand how BT affect the response of GCT to EE2 we ran additional EE2 exposure simulations without BT. Finally, to illustrate a realistic management option, we simulated changes in angling regulations to encourage removal of BT to suppress their populations and thus the degree of competition with GCT. This virtual experiment showed that suppressing BT could make the GCT population more resilient to EE2, particularly if EE2 loading is not very high (Fig. 12). Because both species of trout provide valued FEGS, management of BT by increasing removal by anglers could simultaneously increase the persistence of GCT and help to make the GCT population less susceptible to other stressors, such as toxicants.

\subsection{Valuation of ecosystem services provided by trout}

Economic valuation of the potential benefits of EE2 management would require evaluation of changes in two modeled endpoints that can be related both to FEGS and to beneficiary WTP - i.e., total catch of BT + GCT and change in adult GCT population (see Table 1). We evaluated the implications of changes from the baseline condition, i.e., baseline EE2 loading (EE2 × 1.0), with no management of BT populations. The two loading scenarios selected represent either the achievement of 50\% EE2 control or, for comparison, a doubling of EE2 loadings. The BT management scenario examined increased removal of BT by anglers. Because available benefits-transfer data are based on either numeric or percentage changes in salmonid abundance, we display all changes in both numeric and percentage terms (Table 2). Whereas we use the "Mean time to extirpation of GCT" to compare total value across scenarios, more refined estimates could be made by using metapopulation modeling to account for local extirpations and recolonization.

Without any BT control, the $50 \%$ reduction of EE2 loading resulted in only a slight increase in total salmonid catch, but improvements (25\%) in GCT population abundance. Doubling EE2 loading reduced (-39\%) GCT population abundance (Table 2). The simulated management policy of increased BT removal alone (with no change in EE2) was sufficient to almost completely eliminate BT from the regulated reaches ( $-99.6 \%$; results not shown). The resulting release from competition with BT increased the adult GCT population abundance by $370 \%$, but reduced the combined angling catch by $80 \%$. GCT populations benefited even more from the 50\% EE2 loading reduction However, the population experienced a smaller (34\%) increase relative to the baseline under a scenario with doubled EE2 loading (Fig. 13).
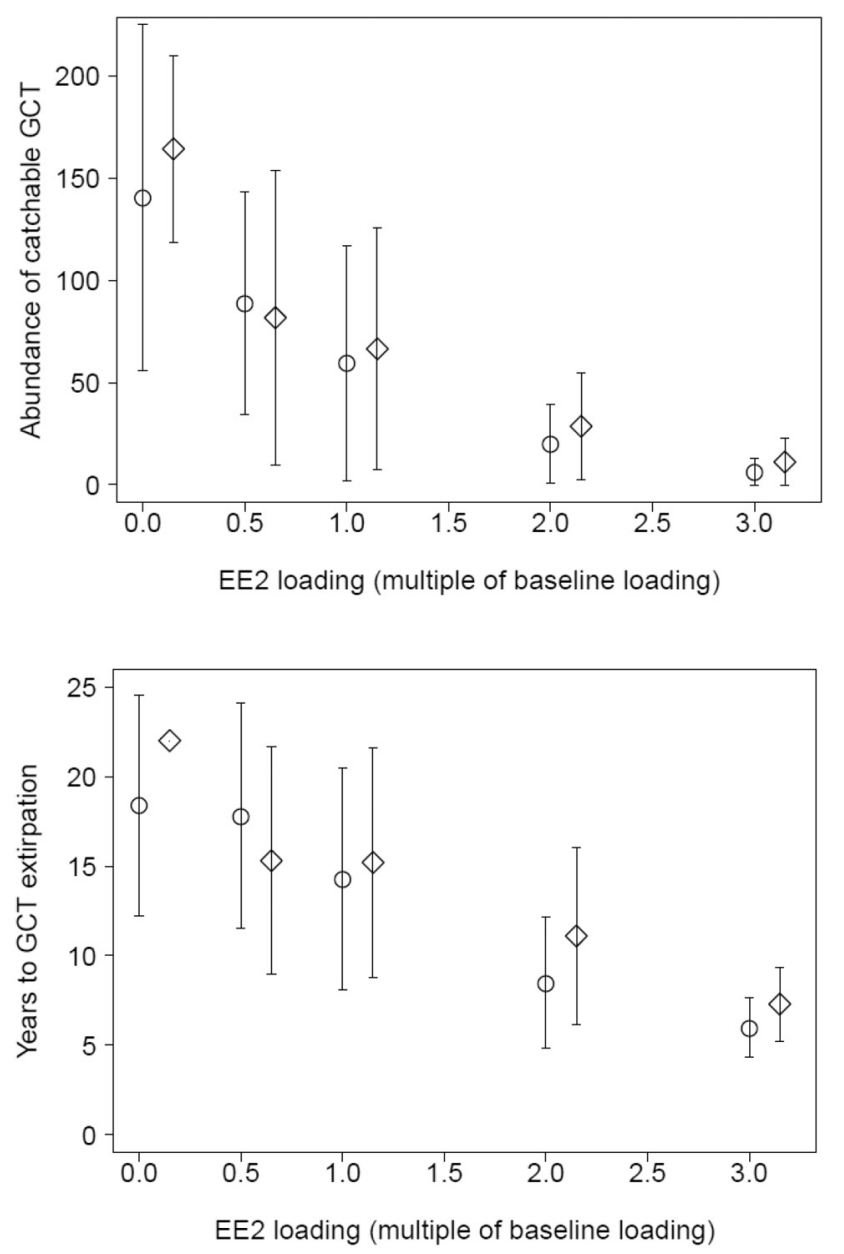

Fig. 12. Effect of BT on the response of GCT to EE2. Top) Effect of EE2 loading on the mean fall abundance (number) of catchable GCT in the absence of BT or with increased BT removal; Bottom) Number of years until extirpation of the simulated GCT population in the absence of BT or with increased BT removal. BT absent = diamonds; Increased BT removal $=$ circles. The baseline loading (factor $=1.0$ on the $\mathrm{X}$ axis) was calibrated to result in an annual average exposure concentration of EE2 of $10 \mathrm{ng} / \mathrm{L}$. Error bars are standard deviations around the mean of 10 replicate simulations. The GCT population persisted the maximum of 22 years in all replicates when EE2 was zero and BT absent.

These results suggest that in streams supporting GCT, both competition from non-native BT populations and high loadings of EE2 could negatively affect GCT populations. Policies to encourage control of BT could, depending on their real-world effectiveness, be as important as or more important than EE2 loading reduction in ensuring GCT survival. The value of a BT control policy, considered apart from EE2 loading mitigation, would entail valuing the nearly 4-fold increase in GCT

Table 2

Modeled endpoints useful for valuation. Numeric (number of fish) and percentage changes in total angling catch and GCT adult population abundance, under differing EE2 loadings and BT management scenarios, as compared to the baseline condition (bold text) of baseline EE2 loading $(E E 2 \times 1.0)$ and no control of BT. Values represent means over 10 simulations.

\begin{tabular}{|c|c|c|c|c|c|}
\hline \multirow[b]{2}{*}{ Loading } & \multirow[b]{2}{*}{ Basis } & \multicolumn{2}{|c|}{ No BT Control } & \multicolumn{2}{|c|}{ Increased BT Removal } \\
\hline & & $\begin{array}{l}\text { Catch of } \\
\text { BT + GCT }\end{array}$ & $\begin{array}{l}\text { GCT Adult } \\
\text { Population }\end{array}$ & $\begin{array}{l}\text { Catch of } \\
\text { BT + GCT }\end{array}$ & $\begin{array}{l}\text { GCT Adult } \\
\text { Population }\end{array}$ \\
\hline \multirow[t]{2}{*}{$\mathrm{EE} 2 * 1.0$} & No. & NA & NA & -2157 & 55 \\
\hline & $\%$ & NA & NA & -80.2 & 370 \\
\hline \multirow[t]{2}{*}{$\mathrm{EE} 2 * 0.5$} & No. & 78 & 3.7 & -1911 & 74 \\
\hline & $\%$ & 2.9 & 25.1 & -71.1 & 496 \\
\hline \multirow[t]{2}{*}{$\mathrm{EE} 2 * 2.0$} & No. & -310 & -5.8 & -2521 & 5.0 \\
\hline & $\%$ & -11.5 & -39.1 & -93.8 & 33.7 \\
\hline
\end{tabular}




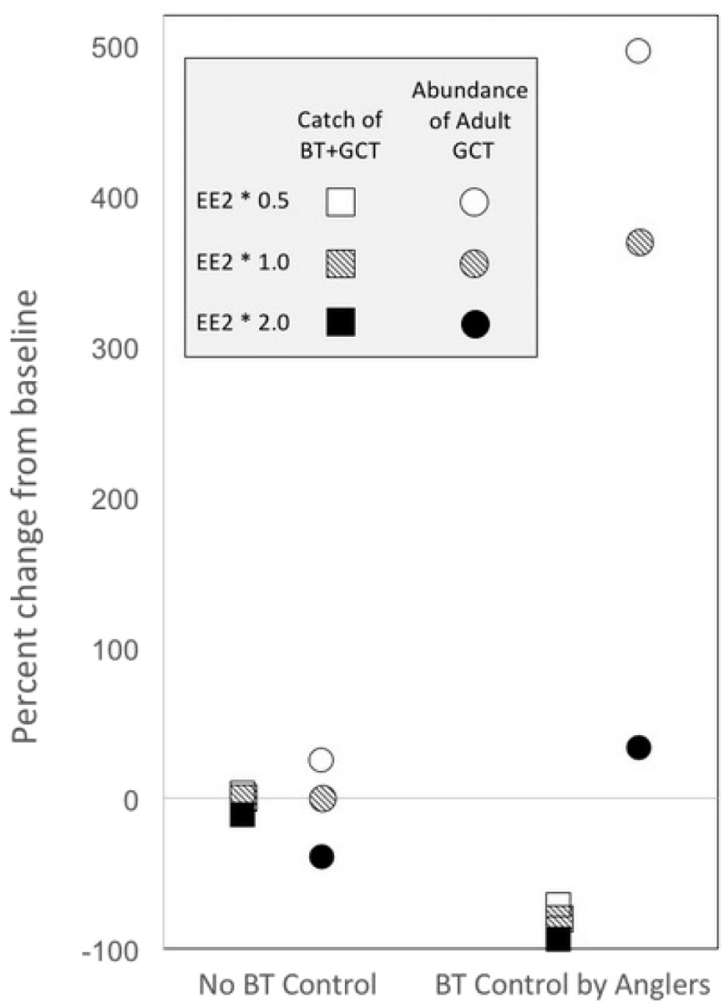

Fig. 13. Percentage change in FEGS (total catch of BT + GCT) and change in adult GCT population in response to EE2 loading scenarios in the presence and absence of BT management.

populations (presumably valued by households across Colorado) against reductions in salmonid catch (important to anglers) and the cost of the program. Because both the numeric catch reductions and the percentage GCT population abundance increases are large, the uncertainties inherent in benefits transfer would require careful evaluation to determine net benefit. Furthermore, society's WTP for preservation can be highly nonlinear; as a species becomes rarer, the risk of extirpation and society's WTP for preservation both increase exponentially (Bulte and van Kooten, 1999; Efroymson et al., 2009). The nonlinear nature of the EE2 loadingresponse relationship also introduces uncertainty. In our simulations, a $50 \%$ reduction in EE2 loading created only modest improvements in the valued endpoints when BT populations were controlled, but a doubling of EE2 reduced the benefits of BT control.

\section{Conclusions}

Our model simulations suggest that among the various mechanisms of EE2 impact on trout reproduction we considered in this study, reduced male readiness might be the dominant effect mechanism for explaining population-level effects. Our simulations suggest that, because not all females spawn every year, EE2 effects on male readiness to spawn are somewhat buffered at the population level. Simulations showed that high EE2 loadings are likely to cause strong populationlevel effects on both trout species and that competition with BT has an even larger negative impact on GCT persistence than EE2. Competition with BT appears to have strong cumulative effects with EE2, and suppression of BT (e.g., via angling regulations) could enable GCT populations to overcome contaminant effects on reproduction. We emphasize that our study provides a proof-of-concept to demonstrate a novel extrapolation framework and does not intend to serve as an actual risk assessment. For the latter, assumptions regarding the mechanistic basis of EE2 effects on trout would need to be revisited and confirmed.

Mechanistic models of the kind used here provide quantitative links from individual to population-level impacts, incorporate ecological complexity in a meaningful way, and improve the usefulness of organismal studies of sublethal effects for risk assessment. Expressing the output of such models in terms of final ecosystem goods and services with direct connections to beneficiaries provides metrics that can be valued, and this can facilitate stakeholder engagement and decision making. In this case, benefits of either BT suppression or EE2 loading mitigation would be experienced differently by two different beneficiary groups for which transferable WTP data were available - anglers, and people in the state of $\mathrm{CO}$ who care about the size of threatened GCT populations. These benefits would need to be weighed against the costs of BT management and wastewater treatment to remove EE2. Quantifying human-caused impacts to ecosystem services produced by nature - in this case trout populations - and expressing these in monetary (or other comparable) units can be helpful, particularly where tradeoffs or synergies among services occur and/or where the costs or consequences of different management options vary widely.

Supplementary data to this article can be found online at https://doi. org/10.1016/j.scitotenv.2018.08.344.

\section{Acknowledgements}

The present study was conducted as part of the Organisms to Ecosystems Working Group at the National Institute for Mathematical and Biological Synthesis, sponsored by the National Science Foundation through award DBI-1300426, with additional support from The University of Tennessee, Knoxville. We thank members of our sister working group (Molecules to Organisms) and in particular Irv Shultz for sharing his extensive trout knowledge and data. This research was coauthored by $\mathrm{HJ}$ at Oak Ridge National Laboratory, which is managed by UTBattelle, LLC, under Contract Number DE-AC05-000R22725 with the U.S. Department of Energy (DOE). The publisher, by accepting the article for publication, acknowledges that the U.S. Government retains a nonexclusive, paid-up, irrevocable, worldwide license to publish or reproduce the published form of this manuscript, or allow others to do so, for U.S. Government purposes. The Department of Energy will provide public access to these results of federally sponsored research in accordance with the DOE Public Access Plan (http://energy.gov/downloads/doe-publicaccess-plan).

Disclaimer: The views expressed in the present article are those of the authors and do not necessarily reflect the views or policies of the US Environmental Protection Agency (USEPA). Mention of trade names, products, or services does not convey and should not be interpreted as conveying official USEPA approval, endorsement, or recommendation.

\section{References}

Bartholomew, A., Bohnsack, J.A., 2005. A review of catch-and-release angling mortality with implications for no-take reserves. Rev. Fish Biol. Fish. 15, 129-154.

Boyd, J.W., Banzhaf, S., 2007. What are ecosystem services? The need for standardized environmental accounting units. Ecol. Econ. 63, 616-626.

Brown, K.H., Schultz, I.R., Nagler, J.J., 2007. Reduced embryonic survival in rainbow trout resulting from paternal exposure to the environmental estrogen $17 \alpha$-ethynylestradiol during late sexual maturation. Reproduction 134, 659-666.

Bulte, E.H., van Kooten, G.C., 1999. Metapopulation dynamics and stochastic bioeconomic modeling. Ecol. Econ. 30, 293-299.

Caldwell, D.J., Mastrocco, F., Anderson, P.D., Länge, R., Sumpter, J.P., 2012. Predicted-no-effect concentrations for the steroid estrogens estrone, $17 \beta$-estradiol, estriol, and $17 \alpha$-ethinylestradiol. Environ. Toxicol. Chem. 31, 1396-1406.

Coleman, M.A., 2007. Life history and ecology of the greenback cutthroat trout. Report by Mark A. Coleman and The Colorado Natural Heritage Program for The Greenback Cutthroat Recovery Team. Colorado State University.

Dudley, P.N., 2018. A salmonid individual-based model as a proposed decision support tool for management of a large regulated river. Ecosphere 9, e02074 n/a.

EC, 2006. Regulation (EC) No 1907/2006 of the European Parliament and of the Council of 18 December 2006 concerning the Registration, Evaluation, Authorisation and Restriction of Chemicals (REACH), establishing a European Chemicals Agency, amending Directive 1999/45/EC and repealing Council Regulation (EEC) No 793/93 and Commission Regulation (EC) No 1488/94 as well as Council Directive 76/769/ EEC and Commission Directives 91/155/EEC, 93/67/EEC, 93/105/EC and 2000/21/EC; 2006. http://eur-lex.europa.eu/legal-content/EN/TXT/PDF/?uri=CELEX:02006R190720161011\&from=EN, Accessed date: 19 September 2017. 
Efroymson, R.A., Jager, Y., Dale, V.H., Westervelt, J.D., 2009. A framework for developing management goals for species at risk and application to military installations in the United States. Environ. Manag. 2009 (44), 1163-1179.

Forbes, V.E., Calow, P., 2013. Developing predictive systems models to address complexity and relevance for ecological risk assessment. Integr. Environ. Assess. Manag. 9, e75-e80.

Forbes, V.E., Calow, P., Sibly, R.M., 2008. The extrapolation problem and how population modeling can help. Environ. Toxicol. Chem. 27, 1987-1994.

Forbes, V.E., Salice, C.J., Birnir, B., Bruins, R.J.F., Calow, P., Ducrot, V., Galic, N., Garber, K., Harvey, B.C., Jager, H., Kanarek, A., Pastorok, R., Railsback, S.F., Rebarber, R., Thorbek, P., 2017. A framework for predicting impacts on ecosystem services from (sub)organismal responses to chemicals. Environ. Toxicol. Chem. 36, 845-859.

Grimm, V., Martin, B., 2013. Mechanistic effect modeling for ecological risk assessment: where to go from here? Integr. Environ. Assess. Manag. 9, 58-63.

Harvey, B.C., Railsback, S.F., 2012. Effects of passage barriers on demographics and stability properties of a virtual trout population. River Res. Appl. 28, 479-489.

Holmes, T.P., Bergstrom, J.C., Huszar, E., Kask, S.B., Orr, F., 2004. Contingent valuation, net marginal benefits and the scale of riparian ecosystem restoration. Ecol. Econ. 49, 19-30.

Hommen, U., Forbes, V., Grimm, V., Preuss, T.G., Thorbek, V., Ducrot, V., 2015. How to use mechanistic effect models in environmental risk assessment of pesticides: case studies and recommendations from the SETAC workshop MODELINK. Integr. Environ. Assess. Manag. 12, 21-31.

Kolpin, D.W., Furlong, E.T., Meyer, M.T., Thurman, E.M., Saugg, S.D., Barber, L.B., Buxton, H.T., 2002. Pharmaceuticals, hormones, and other organic wastewater contaminants in U.S. streams, 1999-2000: a national reconnaissance. Environ. Sci. Technol. 2002, 1202-1211.

Landers, D., Nahlik, A., 2013. Final Ecosystem Goods and Services Classification System (FEGS-CS). U.S. Environmental Protection Agency, Washington, DC (EPA/600/R-13/ ORD-004914)

Loomis, J., 2005. The Economic Value of Recreational Fishing \& Boating to Visitors and Communities Along the Upper Snake River. Final Report. May 1. Dept. of Agricultural and Resource Economics, Colorado State University, Fort Collins, CO https://doi.org/ 10.1016/j.ecolecon.2012.01.00197 pp.

Loomis, J., Richardson, L., 2008. Technical Documentation of Benefit Transfer and Visitor Use Estimating Models of Wildlife Recreation, Species and Habitats. June. Dept. of Agricultural and Resource Economics, Colorado State University, Fort Collins, CO (45 pp.)

Marty, M.S., Blankinship, A., Chambers, J., Constantine, L., Kloas, W., Kumar, A., Lagadic, L. Meador, J., Pickford, D., Schwarz, T., Verslycke, T., 2017. Population-relevant endpoints in the evaluation of endocrine-active substances (EAS) for ecotoxicologica hazard and risk assessment. Integr. Environ. Assess. Manag. 13, 317-330.

McHugh, P., Budy, P., 2006. Experimental effects of nonnative brown trout on the individual-and population-level performance of native Bonneville cutthroat trout. Trans. Am. Fish. Soc. 135, 1441-1455.

McKane, R.B., Brookes, A., Djang, K., Russell, M., 2014. A Community-based Decision Support Tool for Flexible, Interactive Assessments That Quantify Tradeoffs in Ecosystem Goods and Services for Alternative Decision Scenarios in the Pacific Northwest. US Environmental Protection Agency Office of Research and Development, Corvallis (OR) (23 pp.).

MEA, 2005. Millennium Ecosystem Assessment. 2005. Ecosystems and Human WellBeing: Synthesis. Island, Washington, DC.
Milardi, M., Siitonen, S., Lappalainen, J., Liljendahl, A., Weckström, J., 2016. The impact of trout introductions on macro- and micro-invertebrate communities of fishless boreal lakes. J. Paleolimnol. 55, 273-287.

Nahlik, A.M., Kentula, M.E., Fennessy, M.S., Landers, D.H., 2012. Where is the consensus? A proposed foundation for moving ecosystem service concepts into practice. Ecol. Econ. 77, 27-35.

Newbold, S., Simpson, D.R., Massey, M.D., Heberling, M.T., Wheeler, W., Corona, J., Hewitt, J., 2018. Benefit transfer challenges: perspectives from U.S. practitioners. Environ. Resour. Econ. 69, 467-481.

Nienstedt, K., Brock, T., van Wensem, J., Montforts, M., Hart, A., Hardy, A., Aagaard, A., Alix, A., Boesten, J., Bopp, S.K., Brown, C., Capri, E., Forbes, V.E., Köpp, H., Liess, M., Luttik, R., Maltby, L., Sousa, P., Streissl, F., 2012. Development of a framework based on an ecosystem services approach for deriving specific protection goals for environmental risk assessment of pesticides. Sci. Total Environ. 415, 31-38.

Power, A.G., 2010. Ecosystem services and agriculture: tradeoffs and synergies. Philos. Trans. R. Soc., B Biol. Sci. 365, 2959-2971.

Railsback, S.F., Harvey, B.C., Jackson, S.K., Lamberson, R.H., 2009. InSTREAM: The individual-based stream trout research and environmental assessment model. General Technical Report PSW-GTR-218. U. S. Department of Agriculture Forest Service, Pacific Southwest Research Station, Albany, CA (254 pages).

Railsback, S.F., Harvey, B.C., White, J.L., 2015. Effects of spatial extent on modeled relations between habitat and salmon spawning success. Trans. Am. Fish. Soc. 144, 1220-1236.

Schubert, S., Peter, A., Burki, R., Schönenberger, R., Suter, M.J.-F., Segner, H., BurkhardtHolm, P., 2008. Sensitivity of brown trout reproduction to long-term estrogenic exposure. Aquat. Toxicol. 90, 65-72.

Schultz, I.R., Skillman, A., Nicolas, J.-M., Cyr, D.G., Nagler, J.J., 2003. Short-term exposure to $\alpha$-ethynylestradiol decreases the fertility of sexually maturing male rainbow trout (Oncorhynchus mykiss). Environ. Toxicol. Chem. 22, 1272-1280.

Schultz, I.R., Nagler, J.J., Brown, K., 2012. Endocrine disruptors (xeno-estrogens) cause aneuploidy in the sperm and offspring of fish. Environ. Mol. Mutagen. 53 (S1), S21.

Schultz, I.R., Nagler, J.J., Brown, K., 2013. EE2 exposure and mechanisms of aneuploidy and infertility in fish. Oral Presentation at the 17th Pollutant Responses in Marine Organisms Conference, May 5-8, 2013, Faro, Portugal.

Stark, J.D., Banks, J.E., 2003. Population-level effects of pesticides and other toxicants on arthropods. Annu. Rev. Entomol. 48, 505-519.

Strange, E.M., Moyle, P.B., Foin, T.C., 1992. Interactions between stochastic and deterministic processes in stream fish community assembly. Environ. Biol. Fish 36, 1-15.

US EPA, 2017. United States Environmental Protection Agency: The Frank R. Lautenberg chemical safety for the 21st century act. www.epa.gov/assessing-and-managingchemicals-under-tsca/frank-r-lautenberg-chemical-safety-21st-century-act-1, Accessed date: 19 September 2017.

USFWS, 1998. United States Fish and Wildlife Service. Greenback Cutthroat Recovery Plan. U.S. Fish and Wildlife Service, Region 6, Denver, CO.

USFWS, 2017. United States fish and wildlife service. https://ecos.fws.gov/ecp0/profile/ speciesProfile? spcode=E00F, Accessed date: 14 September 2017.

Werner, J., Palace, V.P., Wautier, K.G., Mills, K.H., Chalanchuk, S.M., Kidd, K.A., 2006. Reproductive fitness of lake trout (Salvelinus namaycush) exposed to environmentally relevant concentrations of the potent estrogen ethynylestradiol (EE2) in a whole lake exposure experiment. Sci. Mar. 70, 59-66.

Wilson, M.A., Carpenter, C.R., 1999. Economic valuation of freshwater ecosystem services in the US 1971-1997. Ecol. Appl. 9, 772-783. 